\title{
Utilization of grass and legume fibre and vegetable oil as dietary supplements on village chicken layer production under free range production system
}

\begin{abstract}
This study was carried out to determine the effects of fibre (Leucaena - Leucaena leucocephala and Napier grass - Pennisetum purpureum) and vegetable oil sources (linseed oil and palm oil) on the egg production (EP), egg weight (EW), percentage of hen daily average egg production (\%HDA), feed intake (FI), and feed conversion ratio (FCR). Hens were divided into five groups. One basal diet (BD) was used in the experiment as control group. There were 4 experimental groups which were supplemented with various sources of fibre and oil as follows: Group1: BD + 5\% linseed oil, Group 2: BD + 5\% palm oil, Group 3: $\mathrm{BD}+5 \%$ palm oil plus $2.5 \%$ Napier grass and Group $4: \mathrm{BD}+5 \%$ linseed oil plus $2.5 \%$ Leucaena leaf, respectively. The experiment lasted for 12 weeks. It was observed that there was significant difference (P0.05) was observed on feed conversion ratio (FCR) and feed intake in free range production systems. The lowest feed intake among treatments was belonged to treatment which was included with linseed oil plus Leucaena while the highest feed consumption is from group which was contained palm oil. The highest egg weight among treatments was from treatment which used palm oil plus Napier grass in free range farming system. The highest number of egg production was from treatment contained palm oil plus Napier grass while the lowest egg production was belonged to control group.
\end{abstract}

Keyword: Plant fibre; Vegetable oil; Free range system; Layer breeder; Village chicken performance 